\title{
Childhood risk factors for developing fibromyalgia
}

This article was published in the following Dove Press journal:

Open Access Rheumatology: Research and Reviews

17 December 2012

Number of times this article has been viewed

\section{Patrick Olivieri' \\ Bruce Solitar ${ }^{2, *}$ \\ Michel Dubois ${ }^{3, *}$}

'NYU School of Medicine, New York, NY, USA; ${ }^{2}$ Department of Rheumatology, ${ }^{3}$ Department of Pain Management, New York University Langone Medical Center, New York, NY, USA

*These authors contributed equally to this work
Correspondence: Patrick Olivieri 334 East 26th Street, Apt I8cI, New York, NY 10010, USA

Tel +l 2018898827

Email olivieri.patrick@gmail.com
Background: Fibromyalgia is a disease process without an obvious etiology. While some evidence suggests that adverse experiences in childhood contribute to its development, specific evidence has been equivocal.

Methods: A total of 36 patients with fibromyalgia from the greater New York area were recruited and surveyed using the Centers for Disease Control's Behavioral Risk Factor Surveillance System survey, and questions from the section on adverse childhood experiences were administered. The results were compared to those obtained from over 400,000 people surveyed by the Centers for Disease control each year, and were monitored for statistically significant differences.

Results: A statistically significant difference was noted among the control group, suggesting that individuals reported growing up with someone who was depressed when the respondents were between the ages of 0 and 18 years old. Moreover, respondents reported that they were hit by their parents in some way, were insulted or cursed at by their parents, and had been forced to have sex with someone at least 5 years older than them or with an adult. No correlation was found with the following variables and the development of fibromyalgia: growing up with divorced or separated parents; growing up with someone sentenced to serve time in jail; or having parents that abused each other. Additionally, statistically significant differences were found for the following categories: lack of emotional support; life dissatisfaction; fair or poor health; physical, mental or emotional disability; and being divorced or not married.

Discussion: Using this well-validated survey, it became clear that at least six specific adverse childhood experiences were correlated with the development of fibromyalgia. Data pertaining to disability, quality of life, life satisfaction, number of days of depression, emotional support, and marriage status illustrated the extent of subjective disability that these patients feel every day.

Keywords: fibromyalgia, adverse childhood events, risk factors

\section{Background}

Fibromyalgia (FM) is a chronic condition affecting $2 \%$ of people in the United States. ${ }^{1}$ FM is characterized by chronic widespread pain, both hyperalgesia and allodynia, often leading to severe fatigue. ${ }^{2,3}$ The American College of Rheumatology's preliminary diagnostic criteria for FM include having a Widespread Pain Index $\geq 7$ and a Symptom Severity Scale score of 5 (or a Widespread Pain Index of 3-6 and a Symptom Severity scale score $\geq 9$ ), the presence of symptoms that occurred at a similar level for at least 3 months, and the patient not having another disorder which would otherwise explain the pain. ${ }^{4}$ Though FM is believed to be a disorder of central pain processing, ${ }^{5,6}$ there are many widespread theories that have yet to yield definitive results. ${ }^{7-12}$ 
Adverse childhood experiences have been proposed to be linked to FM as well. These incidents range from emotional, physical, and sexual abuse to "traumatic experiences."13-16 Unfortunately, the specific situations occurring during childhood have not been well studied, and data have broadly classified all incidents in the category of adverse childhood experiences.

It has further been documented that the disease carries a high comorbidity of depression and anxiety. ${ }^{17}$ For comparison, FM patients scored the lowest on a mental component of a quality of life questionnaire, compared to patients with ankylosing spondylitis and rheumatoid arthritis. ${ }^{18}$ Unfortunately, there is still a lack of knowledge about these trends among the general public.

Beyond the broad associations made with regard to childhood experiences, previous research has yet to use the core Behavioral Risk Factors Surveillance System (BRFSS) survey, which is used annually by the Centers for Disease Control (CDC). This survey was used by approximately 420,000 Americans in 2009, and is well-validated; ${ }^{19}$ in addition, data collected through this survey date back to 1984 , when the survey was first implemented. ${ }^{20}$

While treatment is available for FM, many patients continue to experience significant disability. The goal of this study is to identify specific risk factors associated with the development of FM, particularly those that occur in childhood.

\section{Methods}

This study was conducted on patients with FM that were mostly seen in a private rheumatology practice, as well as on several patients seen at the New York University Pain Management Center. The patients included in the study lived primarily in the greater New York City area at the time the study was conducted, and they must have been diagnosed with FM for at least 30 days based on their clinical presentation according to The American College of Rheumatology 1990 classification criteria for the diagnosis of FM. ${ }^{21}$ Overall, 36 patients (31 females, five males) were interviewed between August and December, 2010. The participants were interviewed at an average of 11.4 years (range: 0-25 years) after their initial diagnosis of FM. All patients were at least 18 years of age and did not have another chronic condition that would preclude them from this study based on the opinion of the principal investigator.

The BRFSS survey, an annual epidemiology tool used by the CDC, was administered to all subjects. It has been shown that most questions on this survey are at least moderately valid and reliable. ${ }^{19}$ This survey was not administered in its entirety, and questions were limited to those from the core component, as well as from a section on adverse childhood experiences. A brief medical history was collected from each participant at the end of the interview to ensure that each subject would not be precluded from participation.

Informed consent was obtained from each participant before each interview, and an information sheet about the study was given to each patient before questioning. After institutional review board approval, consented subjects were verbally asked questions from the BRFSS survey, which was read in the exact wording and with the specific instructions outlined by the CDC's BRFSS survey instructions. All interviews were conducted in the same manner. No personally identifiable information was recorded, and the surveys were stored until all the patients had completed the study. After all subjects had completed this questionnaire, the data were analyzed for statistically significant trends.

In the section of the survey titled "Adverse Childhood Experiences," patients were asked to answer a set of eleven questions about their lives between the ages of 0 and 18 years, to the best of their memory. These questions involved whether the patient lived with anyone who was depressed, mentally ill, or suicidal; a problem drinker or an alcoholic; had used illegal street drugs or abused prescription medications; or was sentenced to serve time in a correctional facility. This section asked several questions about the subject's parents, specifically whether they were separated or divorced, whether they had hit each other or the subject (excluding spanking), and whether the parents had verbally abused the patient. This section ended with a set of three sensitive questions; these questions asked whether anyone at least 5 years older than the subject, or an adult, had tried to touch the subject in a sexual way, whether they had succeeded, and whether that person had forced the subject to have sex with them. Patients were provided with contact information for the National Hotline for child abuse following the questionnaire, if they so desired this information.

To control for disparities between the study group and the BRFSS population, patients were asked a number of other neutral questions, which have been known to influence health outcomes. Among these, patients were asked if they had smoked at least 100 cigarettes in their lifetime, their age, whether they had exercised in the past 30 days, and whether they had used alcohol in the past 30 days. In addition, several questions were asked regarding the participants' sleeping habits, level of education, ethnicity, and marital status. Subjects 
were also asked if they had received a tetanus shot in the past 10 years, and whether they had arthritis.

Analysis was done primarily via chi-squared analysis, using a calculator for chi-squared data from the University of Kansas. ${ }^{22}$ Most data were analyzed using a $2 \times 2$ cell analysis, with the control group being the population sampled by the CDC, and the study group being the 36 patients interviewed for this study. If a subject declined to answer a question, then only the data from those patients who chose to answer the question were used in the analysis. The sample taken from the CDC data was determined using raw frequencies from the codebook, as used by the CDC. ${ }^{19}$ A Student's $t$-test was performed on age. Overall, the power of these results was 0.80 .

\section{Results}

The CDC population used for comparison contained 432,607 participants; the demographic information for these participants is summarized in Table 1. The mean age for the CDC population was estimated to be 55.9 years, where the mean age for the FM patients was 54.2 years $(P=0.237)$. A total of $31 \mathrm{FM}$ patients were female and five were male, as compared to 163,961 males and 268,646 females in the CDC population $(P<0.001)$. Results refer to these 36 FM subjects, unless otherwise specified.

A total of 20 participants reported having smoked less than 100 cigarettes in their lifetime $(P=0.838)$. In addition, 23 patients reported having received a tetanus shot in the past 10 years, with 12 denying ever having received this injection $(P=0.622)$.

Table I Demographic characteristics

\begin{tabular}{|c|c|c|c|}
\hline Demographic & $\begin{array}{l}\text { FM group } \\
(\%)\end{array}$ & $\begin{array}{l}\text { BRFSS group } \\
\text { (\%) }\end{array}$ & $P$-value \\
\hline Population & 36 & 432,607 & $<0.001$ \\
\hline Female & $31(86)$ & $268,646(62)$ & $<0.001$ \\
\hline Male & $5(14)$ & $|63,96|(38)$ & $<0.001$ \\
\hline Mean age & 54.2 & 55.9 & 0.237 \\
\hline \multicolumn{4}{|l|}{ Marital status } \\
\hline Married & $9(25)$ & $242,99 \mid(60)$ & $<0.001$ \\
\hline Divorced & II (3I) & $58,985(14)$ & $<0.001$ \\
\hline Widowed & $3(8)$ & $61,107(14)$ & 0.314 \\
\hline Separated & $2(6)$ & 8715 & $0.36 \mathrm{I}$ \\
\hline Never married & $10(28)$ & $49,602(11)$ & 0.005 \\
\hline Unmarried couple & $2(6)$ & $9318(2)$ & 0.409 \\
\hline Overall health good or better & $15(42)$ & $214,174(56)$ & $<0.001$ \\
\hline Recent exercise & $25(69)$ & $313,442(75)$ & 0.677 \\
\hline Recent alcohol use & $20(56)$ & $202,459(5 I)$ & 0.347 \\
\hline $100+$ cigarettes in lifetime & $20(56)$ & $199,479(42)$ & 0.838 \\
\hline Tetanus vaccine up to date & $23(6)$ & $40,011(64)$ & 0.622 \\
\hline Females with mammogram & $25(8 \mathrm{I})$ & II,4I6 (79) & 0.956 \\
\hline
\end{tabular}

Abbreviations: FM, fibromyalgia; BRFSS, Behavioral Risk Factor Surveillance System.
Table 2 Adverse childhood experiences

\begin{tabular}{|c|c|c|c|}
\hline Finding & $\begin{array}{l}\text { FM patients } \\
\text { (\%) }\end{array}$ & $\begin{array}{l}\text { BRFSS } \\
\text { population (\%) }\end{array}$ & $P$-value \\
\hline $\begin{array}{l}\text { Growing up with depressed } \\
\text { person }\end{array}$ & 47 & 15 & $<0.001$ \\
\hline Physical abuse from parents & 42 & 10 & $<0.001$ \\
\hline Verbal abuse from parents & 53 & 23 & $<0.001$ \\
\hline Touched sexually by adult & 26 & 9 & $<0.001$ \\
\hline $\begin{array}{l}\text { Attempted to be touched } \\
\text { sexually by adult }\end{array}$ & 34 & 6 & $<0.001$ \\
\hline $\begin{array}{l}\text { Forced to have sex } \\
\text { with adult }\end{array}$ & 21 & 4 & $<0.001$ \\
\hline Lived with alcoholic & 17 & 23 & $<0.242$ \\
\hline Parents separated/divorced & 25 & 26 & $<0.641$ \\
\hline Parents abused each other & 17 & 15 & $<0.813$ \\
\hline $\begin{array}{l}\text { Lived with sentenced family } \\
\text { member }\end{array}$ & 3 & 7 & $<0.869$ \\
\hline Lived with drug addict & 9 & 10 & $<0.975$ \\
\hline
\end{tabular}

Abbreviations: FM, fibromyalgia; BRFSS, Behavioral Risk Factor Surveillance System.

Several trends were identified in participants' responses from the Adverse Childhood Experiences section; results are listed in Table 2. Statistically significant results were found for growing up with a depressed person, being hit by one's parents, being insulted by one's parents, and surviving all of the three types of sexual assault $(P<0.001$ across all categories).

For the remainder of the questions from the Adverse Childhood Experiences section, six subjects reported having lived with a problem drinker or alcoholic, while 30 denied this $(P=0.242)$. Moreover, three patients reported having lived with someone who used illegal street drugs or abused prescription medications, while 32 denied having experienced this type of situation $(P=0.975)$. One patient reported having lived with someone sentenced to serve time in a correctional facility, with 35 patients reported having experienced no such incident $(P=0.865)$. Nine patients reported that their parents were separated or divorced, while 27 denied this $(P=0.641)$. Six patients reported having been aware of their parents engaging in physical violence towards one another, while 30 denied having had this knowledge $(P=0.813)$. Select results are highlighted in Figure 1.

A total of 15 subjects rated their overall health as good or better, while 21 rated their overall health as fair or worse. In addition, 31 patients reported being disabled in some way, compared to five who were not. Moreover, 18 of 36 patients stated that they "always" or "usually" received the support they needed, while the other 18 respondents indicated that they "sometimes," "rarely," or "never" received the support they needed. Similarly, 17 patients reported being satisfied 


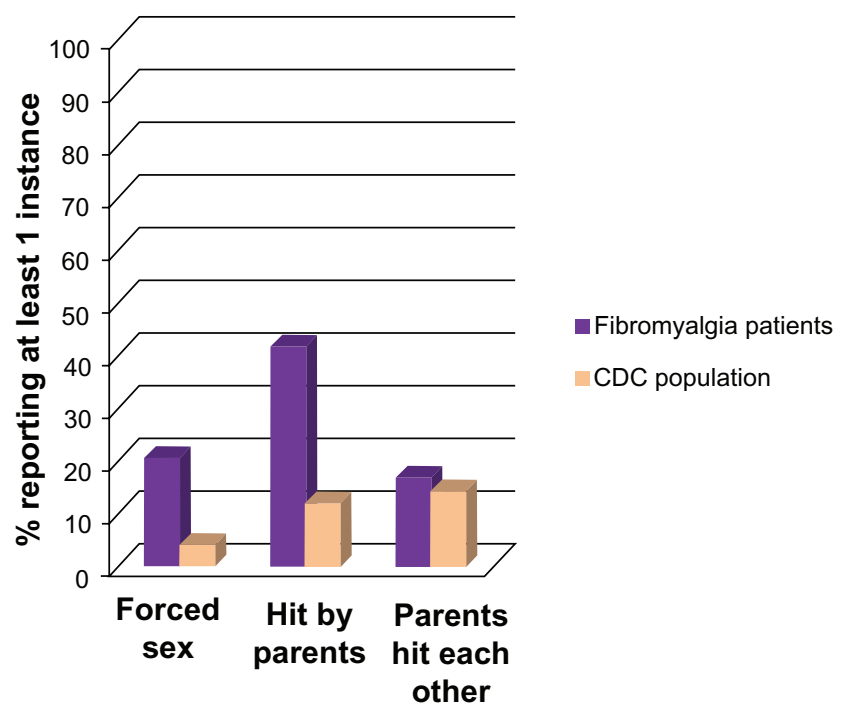

Figure I Comparison of the rate of responses to three questions from the Adverse Childhood Experience section between fibromyalgia patients and the CDC population.

Notes: With all questions referring to the subjects when they were between the ages of 0 and 18 years, the first question refers to whether the subject was forced to have sex; the second refers to whether the subject was hit by his or her parents (excluding spanking); and the third asks whether the subject's parents hit each other.

Abbreviation: CDC, Centers for Disease Control.

or very satisfied with their life overall, while 17 reported being dissatisfied or very dissatisfied. All of these results were found to be statistically significant, corresponding to a $P$-value $<0.001$ across all responses.

Our patients reported that, over the preceding 30 days, pain had made it difficult for them to perform usual activities for an average of 21.6 days. Patients further reported that they had felt depressed for an average of 15.3 days, worried for 18.8 days, and had not received enough rest for an average of 20.2 days.

\section{Discussion}

The Adverse Childhood Experiences section of the BRFSS survey revealed interesting and informative data that helped strengthen the belief that traumatic childhood experiences are correlated with the development of FM. Specifically, the responses on these survey items helped clarify which specific childhood events increased one's risk of developing FM. In general, it appears that negative experiences in one's childhood that are specifically targeted against the child (like being physically abused by one's parents) tended to be more statistically significant than negative events that simply surrounded the patient as a child (eg, parents physically abusing one another, but not the child).
We found that the results obtained from our population and those obtained from the CDC were similar across several important demographics. The high $P$-values associated with having received a tetanus shot and a mammogram imply that all respondents (FM patients and members of the general population) had reasonably equal access to health care and medical screening. The high $P$-values associated with smoking history, exercise status, alcohol abuse, age, and ethnicity also helped to decrease potential bias in our study. There are, however, several key differences between the responses noted between the two populations including respondents' general overall health, life satisfaction, and amount of pain experienced. There was also an obvious sex discrepancy between the two groups, but this fact has been previously well studied (see, for example, Lawrence et $\mathrm{al}^{23}$ ).

Disease burden had been previously measured, but never against such a large, established control group. As a first point of discussion, it is important to note that there appears to be an extreme perceived lack of social support, as well as a higher tendency for patients to be divorced in the FM group. Data on the total number of days on which patients experienced feeling depressed over the course of the preceding 30 days illustrates the poor quality of life experienced by these patients. Moreover, these symptoms did not tend to improve with time.

The largest bias observed in this study was the sex difference between the two groups. Controlling for sociodemographic factors when analyzing data may have clarified whether these differences (including overall health and employment status) may have affected the reporting of adverse childhood experiences; more research is needed to explain these discrepancies. Further, the FM population may be skewed because it represents patients who have both access to health care and the means to go to a private physician's office. These luxuries are not necessarily true of all CDC participants surveyed.

We cannot definitively say that the adverse childhood experiences mentioned in the present study necessarily contribute to FM given the study's limitations. However, data have been presented, which have described specific events that are more likely to be correlated with the development of FM. We believe that the adverse childhood experiences mentioned in the present study may contribute to the etiology of FM, as compared to the nonsignificant, apparently unrelated experiences. This is consistent with other findings previously reported that have described the link between the early age of traumatic experiences and poor responses to stress. ${ }^{24}$ 
Details on the severity and breadth of problems that FM patients endure on a daily basis have been observed in this study. These results were achieved using a well-validated, broadly used survey to compare patients with FM to a representation of the general population. While these results are promising, more data are needed to specify the exact triggers of FM (if any exist) to help prevent the development of this disease.

\section{Acknowledgments}

Stephanie Ferket contributed greatly to this project. She helped with the inception of the original project, interviewing several patients, and with some data analysis. A special thanks is owed to her.

\section{Disclosure}

PO is a New York University medical student with an interest in musculoskeletal disorders. BS is a clinical associate professor in the Medical Rheumatology Division. MD is a Dr Joyce Lowinson Professor of Pain Medicine and Palliative Care. The authors report no conflicts of interest in this work.

\section{References}

1. Weir PT, Harlan GA, Nkoy FL, et al. The incidence of fibromyalgia and its associated comorbidities: a population-based retrospective cohort study based on International Classification of Diseases, 9th Revision codes. J Clin Rheumatol. 2006;12(3):124-128.

2. Rizzi M, Sarzi-Puttini P, Atzeni F, et al. Cyclic alternating pattern: a new marker of sleep alteration in patients with fibromyalgia? J Rheumatol. 2004;31(6):1193-1199.

3. Amris K, Jespersen A. [Fibromyalgia as a neuropathic pain condition] Ugeskr Laeger. 2010;172(24):1832-1835. Danish.

4. Wolfe F, Clauw DJ, Fitzcharles MA, et al. The American College of Rheumatology preliminary diagnostic criteria for fibromyalgia and measurement of symptom severity. Arthritis Care Res (Hoboken). 2010; 62(5):600-610.

5. Sarzi-Puttini P, Atzeni F, Mease PJ. Chronic widespread pain: from peripheral to central evolution. Best Pract Res Clin Rheumatol. 2011; 25(2):133-139.

6. Staud R. Abnormal pain modulation in patients with spatially distributed chronic pain: fibromyalgia. Rheum Dis Clin North Am. 2009;35(2): 263-274.

7. Wolfe F, Michaud K, Li T, Katz RS. Chronic conditions and health problems in rheumatic diseases: comparisons with rheumatoid arthritis, noninflammatory rheumatic disorders, systemic lupus erythematosus, and fibromyalgia. J Rheumatol. 2010;37(2):305-315.

8. Ortancil O, Sanli A, Eryuksel R, Basaran A, Ankarali H. Association between serum ferritin level and fibromyalgia syndrome. Eur J Clin Nutr. 2010;64(3):308-312.
9. Bartels EM, Dreyer L, Jacobsen S, Jespersen A, Bliddal H, DanneskioldSamsøe B. Fibromyalgia, diagnosis and prevalence. Are gender differences explainable? Ugeskr Laeger. 2010;172(2):156; author reply 156. Danish.

10. Cedraschi C, Allaz AF. How to identify patients with a poor prognosis in daily clinical practice. Best Pract Res Clin Rheumatol. 2005;19(4): 577-591.

11. Clauw DJ. Fibromyalgia: an overview. Am JMed. 2009;122(Suppl 12): S3-S13.

12. Nicolson NA, Davis MC, Kruszewski D, Zautra AJ. Childhood maltreatment and diurnal cortisol patterns in women with chronic pain. Psychosom Med. 2010;72(5):471-480.

13. Häuser W, Kosseva M, Üceyler N, Klose P, Sommer C. Emotional, physical, and sexual abuse in fibromyalgia syndrome: a systematic review with meta-analysis. Arthritis Care Res (Hoboken). 2011;63(6): $808-820$.

14. Kosseva M, Schild S, Wilhelm-Schwenk R, Biewer W, Häuser W. [Comorbid depression mediates the association of childhood/adolescent maltreatment and fibromyalgia syndrome. A study with patients from different clinical settings]. Schmerz. 2010;24(5):474-484. German.

15. Haviland MG, Morton KR, Oda K, Fraser GE. Traumatic experiences, major life stressors, and self-reporting a physician-given fibromyalgia diagnosis. Psychiatry Res. 2010;177(3):335-341.

16. Wilson DR. Health consequences of childhood sexual abuse. Perspec Psychiatr Care. 2010;46(1):56-64.

17. Fietta P, Fietta P, Manganelli P. Fibromyalgia and psychiatric disorders. Acta Biomed. 2007;78(2):88-95.

18. Ovaloyu N, Ovaloyu O, Karadag G. Health-related quality of life in ankylosing spondylitis, fibromyalgia syndrome, and rheumatoid arthritis: a comparison with a selected sample of healthy individuals. Clin Rheumatol. 2011;30(5):655-664.

19. Centers for Disease Control and Prevention. BRFSS annual survey data: States conducting surveillance, by year (1984-2010) [webpage on the Internet]. Atlanta, GA: Centers for Disease Control and Prevention; 2011 [updated May 16, 2011]. Available from: http://www.cdc.gov/ BRFSS/technical_infodata/surveydata/all_years/states_data.htm/. Accessed August 4, 2012.

20. Nelson DE, Holtzman D, Bolen J, Stanwyck CA, Mack KA. Reliability and validity of measures from the Behavioral Risk Factor Surveillance System (BRFSS). Soz Praventivmed. 2001;46 Suppl 1:S3-S42.

21. Wolfe F, Smythe HA, Yunus MB, et al. The American College of Rheumatology 1990 criteria for the classification of fibromyalgia. Report of the Multicenter Criteria Committee. Arthritis Rheum. 1990;33(2): 160-172.

22. Preacher KJ. Calculation for the chi-square test: an interactive calculation tool for chi-square tests of goodness of fit and independence [computer software]. Kristopher J Preacher; 2001 [cited June 23, 2011]. Available from: http://quantpsy.org. Accessed October 30, 2012.

23. Lawrence RC, Felson DT, Helmick CG, et al. Estimates of the prevalence of arthritis and other rheumatic conditions in the United States. Part II Arthritis Rheum. 2008;58(1):26.

24. McCrory E, De Brito SA, Viding E. The link between child abuse and psychopathology: a review of neurobiological and genetic research. $J$ R Soc Med. 2012;105(4):151-156. 


\section{Publish your work in this journal}

Open Access Rheumatology Research and Reviews is an international, peer-reviewed, open access journal, publishing all aspects of clinical and experimental rheumatology in the clinic and laboratory including the following topics: Pathology, pathophysiology of rheumatological diseases; Investigation, treatment and management of rheumatological

diseases; Clinical trials and novel pharmacological approaches for the treatment of rheumatological disorders. The manuscript management system is completely online and includes a very quick and fair peerreview system, which is all easy to use. Visit http://www.dovepress.com/ testimonials.php to read real quotes from published authors.

Submit your manuscript here: http://www.dovepress.com/open-access-rheumatology-research-and-reviews-journal 